\section{Oral midazolam premedication in children: the minimum time interval for separation from parents}

Mark F. Levine MBBCh FRCPC, Isabelle A. Spahr-Schopfer MD, Elizabeth Hartley MD FRCP, Jerrold Lerman MD FRCPC, Bruce MacPherson MD FRCPC
To determine the minimum time interval between oral midazolam $\left(0.5 \mathrm{mg} \cdot \mathrm{kg}^{-1}\right)$ premedication and separation from parents that ensures a smooth separation, 30 children were assigned randomly to one of three groups (ten children per group). The groups differed only in the time interval between administration of midazolam and separation from their parents: 10, 20 or $30 \mathrm{~min}$. Heart rate, systolic blood pressure, and sedation and anxiolysis scores were assessed before midazolam premedication (baseline), at the time of separation from parents, and during the application of a face mask at the induction of anaesthesia. We found that heart rate and systolic blood pressure changes were similar for all three groups throughout the study period. Sedation scores at the time of separation from parents and on application of the mask for all three groups were greater than baseline values. Sedation scores at separation did not differ among the three groups. Anxiolysis values did not differ from baseline values at any time for all three groups. We conclude that children may be separated from their parents as early as ten minutes after receiving oral midazolam, $0.5 \mathrm{mg} \cdot \mathrm{kg}^{-1}$.

Afin de déterminer le délai minimum entre une prémédication de midazolam par voie orale $\left(0,5 \mathrm{mg} \cdot \mathrm{kg}^{-1}\right)$ et une séparation sans heurts d'avec leurs parents, 30 enfants ont été répartis aléatoirement en trois groupes (dix enfants par groupe). Seul le délai entre l'administration du midazolam et la séparation d'avec leurs parents différait d'un groupe à l'autre: 10, 20 ou 30 minutes. La fréquence cardiaque, la pression systolique, le niveau de sédation et d'anxiolyse ont été évalués avant la

\section{Key words}

PREMEDICATION: midazolam;

ANAESTHESIA: paediatric.

From the department of Anaesthesia and the Research Institute, The Hospital for Sick Children, University of Toronto, Toronto, Ontario, Canada.

Address correspondence to: Dr. E. Hartley, Department of Anaesthesia, The Hospital for Sick Children, 555 University

Avenue, Toronto, Ontario, Canada M5G IX8.

Accepted for publication 16th April, 1993. prémédication (valeur de base), au moment de la séparation et pendant l'application du masque facial à l'induction de l'a. nesthésie. Nous avons trouvé que les changements de fréquence cardiaque et de pression artérielle systolique ont été semblables dans les trois groupes au cours de notre étude. Le niveau de sédation à la séparation et l'application du masque a été plus élevé que la valeur de base et n'est pas différent entre les trois groupes. Le niveau d'anxiolyse n'a pas varié de la valeur de base à aucun moment dans les trois groupes. Nous concluons que les enfants peuvent être séparé de leurs parents aussi précocément que 10 minutes après avoir reçu $0,5 \mathrm{mg} \cdot \mathrm{kg}^{-1}$ de midazolam par voie oral.

Oral midazolam is safe and effective for premedication of children scheduled for ambulatory surgery. ${ }^{1,2}$ It has a rapid and reliable onset of action, few side effects and does not delay recovery. McMillan et al. demonstrated that oral midazolam in doses of $0.5,0.75$ and 1.0 $\mathrm{mg} \cdot \mathrm{kg}^{-1}$ produced excellent sedation and anxiolysis scores $15 \mathrm{~min}$ after administration to children $1-6 \mathrm{yr}$ and at the time of separation from parents at $30 \mathrm{~min} .{ }^{1}$ However, the ease of separation from parents was assessed at only one time, $30 \mathrm{~min}$ after oral midazolam premedication. Similarly, Weldon et al. recommended that oral midazolam be given $30-45$ min preoperatively. ${ }^{3}$ It has been our experience, however, that children could be separated from their parents less than $30 \mathrm{~min}$ after receiving oral midazolam without compromising the degree of sedation and anxiolysis. We therefore sought to determine the minimum time interval between administration of oral midazolam $\left(0.5 \mathrm{mg} \cdot \mathrm{kg}^{-1}\right)$ and separation of the children from their parents that would ensure a smooth and calm separation.

\section{Methods}

This randomized study was approved by the Human Subjects Review Committee and written parental consent was obtained. Midazolam $\left(0.5 \mathrm{mg} \cdot \mathrm{kg}^{-1}\right)$ was administered to 30 children, ASA I or II and aged 1-6 years, who 
were scheduled for ambulatory surgery. Exclusion criteria included routine use of sedatives or hypnotics in the month before the study, allergy to benzodiazepines, enrollment in a drug study in the preceding six months, genetic or central nervous system abnormalities and weight $<10 \mathrm{~kg}$. Midazolam $\left(5 \mathrm{mg} \cdot \mathrm{ml}^{-1}\right.$ (parenteral formulation)) was administered in an equal volume of a chocolate-cherry syrup. The children were assigned to one of three groups by random selection: children in Group I were separated from their parents $10 \mathrm{~min}$ after the midazolam, children in Group II were separated 20 min after midazolam and children in Group III were separated $30 \mathrm{~min}$ after midazolam. Heart rate and systolic blood pressure were measured before midazolam administration (baseline) and on application of the face mask on induction of anaesthesia. Sedation and anxiolysis scores were assessed by two blinded observers at baseline, at the time of separation from the parents and on application of the face mask at induction of anaesthesia.

Sedation and anxiolysis were measured on a scale of 1 to 4 (Table I). A sedation or anxiolysis score of 2 or 3 was considered to indicate adequate sedation or anxiolysis. A parental assessment of the degree of sedation and anxiolysis achieved by the midazolam was completed in the postoperative period (Table II).

Sample size was determined using power analysis based on the following assumptions: $90 \%$ of patients who received oral midazolam would be well sedated $30 \mathrm{~min}$ after receiving the midazolam, ${ }^{1} 40 \%$ of patients would be well sedated $10 \mathrm{~min}$ after oral midazolam, $\alpha=0.05$ and $\beta=0.2$.

Parametric data were analyzed using one-way ANOVA and the Student-Neuman-Keuls test. Heart rate and systolic blood pressure were analyzed using the paired $t$ test for within group differences. Non-parametric data were analyzed using the Wilcoxon Rank Sum test, KruskalWallis test and Chi-square analysis. $P<0.05$ was accepted. Interobserver variability of the sedation and anxiety scoring system was assessed for two observers using kappa analysis.

\section{Results}

The two groups were matched for mean age, weight and sex (Table III). Baseline systolic blood pressure, heart rate and sedation and anxiolysis scores did not differ among the groups. After midazolam none of the children was sedated to an extent that they were unarousable during the study period. In addition, there were no episodes of apnoea or airway obstruction after midazolam administration.

Sedation scores increased at the time of separation from parents in all three groups, compared with baseline values. At baseline 25 of the 30 children had a sedation
TABLE I Sedation and anxiolysis levels

\begin{tabular}{ll}
\hline & Score \\
\hline Sedation level & \\
Alert/active & 1 \\
Awake/calm & 2 \\
Drowsy but responds readily to verbal commands, & \\
$\quad$ light touch & 3 \\
Asleep & 4 \\
Anxiolysis level & \\
Tearful/combative & \\
Anxious but easily reassured & 1 \\
Calm & 2 \\
Asleep & 3 \\
\hline
\end{tabular}

TABLE II Postoperative parental questionnaire

1 Did you feel that your child was adequately relaxed while waiting for surgery?

2 Did you feel that your child was adequately relaxed at the time he/ she was separated from you to enter the operating room?

score of 1 (alert/active) and the remaining five had a sedation score of 2 (awake and calm) compared with three children with a sedation score of 1,18 with a sedation score of 2 and nine children with a sedation score of 3 (drowsy) at the time of separation from parents (Figure 1). At induction of anaesthesia and mask application, sedation scores exceeded the baseline values in all three groups. Twenty-six of the 30 children had a sedation score of 2 or 3 at induction of anaesthesia (Figure 1). Sedation scores were similar for all three groups at separation and on mask application (Figure 1). Anxiolysis scores in all three groups remained unchanged during the study period when compared to baseline (Figure 2). There was complete agreement $(K=1)$ between observers for all anxiety and sedation scores as assessed by kappa analysis.

At the time of face mask application heart rate increased compared with baseline values for all three groups but this reached statistical significance only in the 30min interval group. Similarly, systolic blood pressure increased at the time of mask application in all three groups. This was statistically significant in the 20 and $30 \mathrm{~min}$ interval groups (Table IV).

Twenty-nine of the 30 parents responded to the parental questionnaire that they believed their children were adequately relaxed while waiting for surgery and at the time of separation to enter the operating room (Table II).

\section{Discussion}

The optimal time interval from premedication until separation from parents should provide maximum sedation 
TABLE III Demographic data

\begin{tabular}{lllll}
\hline & $\begin{array}{l}\text { Number of } \\
\text { patients }\end{array}$ & $\begin{array}{l}\text { Age } \pm S D \\
(y r)\end{array}$ & $\begin{array}{l}\text { Weight } \pm S D \\
(\mathrm{~kg})\end{array}$ & Male:female \\
\hline Group I: $10 \mathrm{~min}$ & 10 & $3.7 \pm 1.4$ & $16.5 \pm 4.0$ & $6: 4$ \\
Group II: $20 \mathrm{~min}$ & 10 & $4.1 \pm 1.3$ & $17.8 \pm 4.7$ & $7: 3$ \\
Group III: $30 \mathrm{~min}$ & 10 & $3.8 \pm 1.5$ & $16.4 \pm 4.4$ & $5: 5$ \\
\hline
\end{tabular}

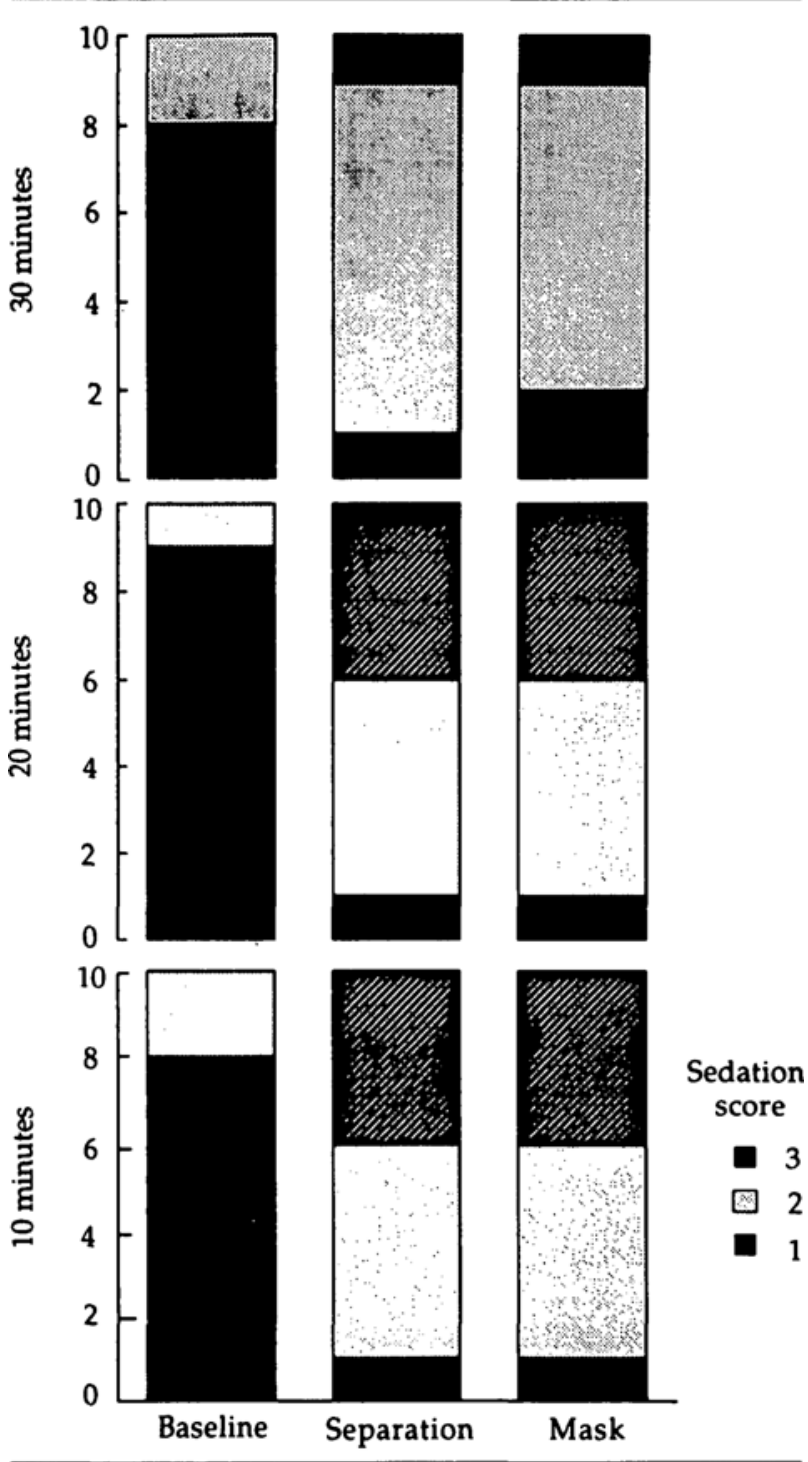

FIGURE 1 Sedation scores in the 10,20 and 30 min groups at baseline (before administration of midazolam), separation and mask application. *Within group difference compared to baseline, $P<0.05$.

and anxiolysis at the time of separation from parents or guardians and at application of a face mask for induction of anaesthesia. Previous studies have reported sedation and anxiolysis measurements between 15 and $30 \mathrm{~min}$ after oral midazolam. ${ }^{1,2}$ The results of those studies supported the efficacy of midazolam. However, it is
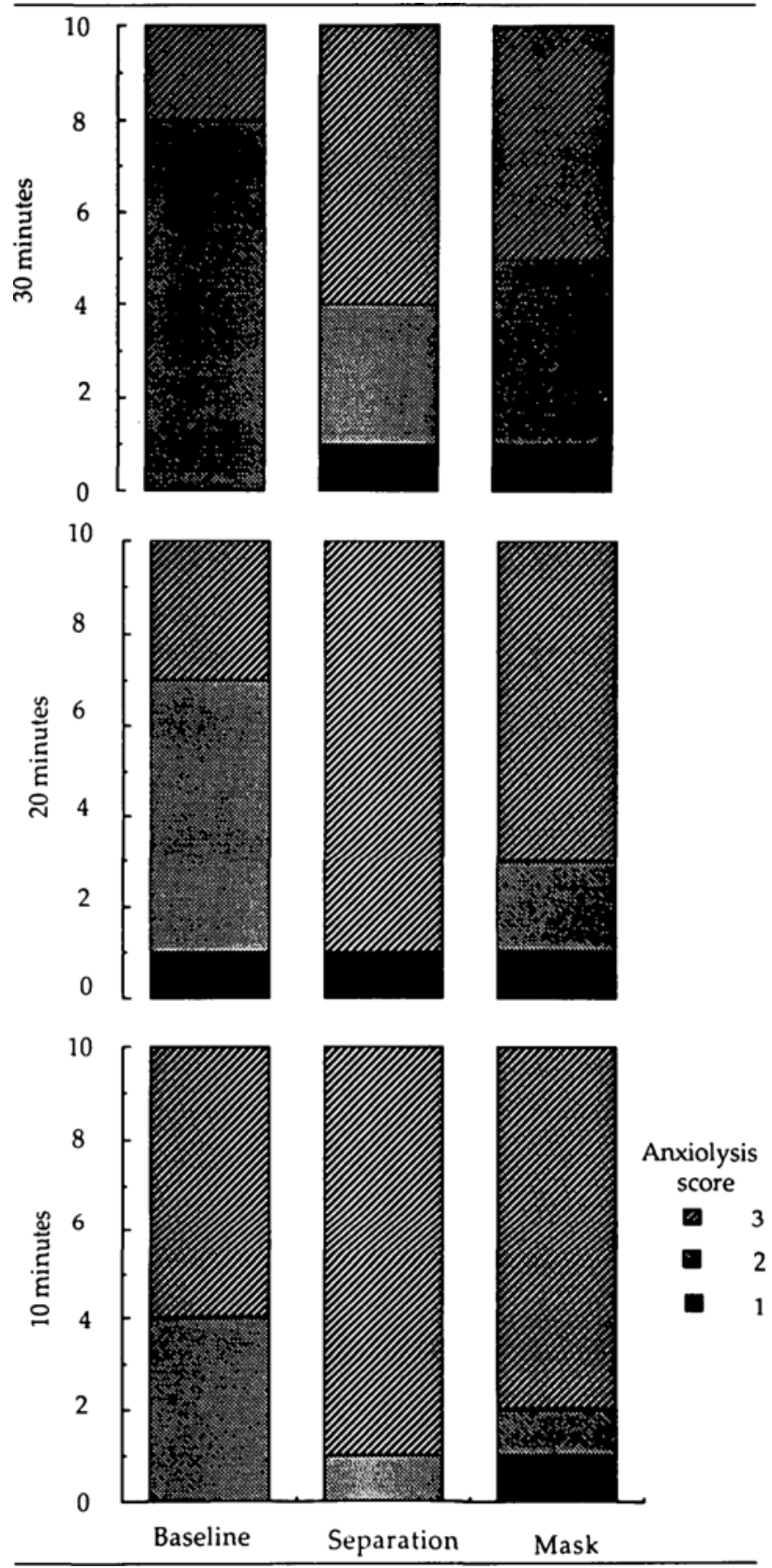

FIGURE 2 Anxiolysis scores in the 10,20 and 30 min groups at baseline (before administration of midazolam), separation and mask application.

important to determine a minimum time interval after oral midazolam to achieve a desired effect in children. 
TABLE IV Haemodynamic data

\begin{tabular}{lclll}
\hline & $\begin{array}{l}\text { Heart rate } \\
\left(b \cdot \text { min }^{-1}\right) \\
\text { Baseline }\end{array}$ & $\begin{array}{l}\text { Heart rate } \\
\left(b \cdot \text { min }^{-1}\right) \\
\text { Mask application }\end{array}$ & $\begin{array}{l}\text { Systolic } \\
B P(\text { mmHg) } \\
\text { Baseline }\end{array}$ & $\begin{array}{l}\text { Systolic } \\
\text { BP (mmHg) }\end{array}$ \\
$\begin{array}{lclll}\text { Mask application } \\
\text { Group I: } 10 \mathrm{~min}\end{array}$ & $98.3 \pm 13.0$ & $112.3 \pm 33.8$ & $96.7 \pm 18.3$ & $107.3 \pm 14.1$ \\
Group II: $20 \mathrm{~min}$ & $109.4 \pm 23.8$ & $117.9 \pm 14.6$ & $98.8 \pm 10.4$ & $109.5 \pm 8.9^{*}$ \\
Group III: $30 \mathrm{~min}$ & $105.4 \pm 10.0$ & $120.9 \pm 16.9^{*}$ & $88.2 \pm 10.4$ & $105.0 \pm 9.0^{*}$ \\
\hline
\end{tabular}

All data expressed as mean $\pm S D$.

${ }^{*} P<0.05$ compared with baseline.

We compared both sedation and anxiety scores at separation from parents or guardians and on mask application in children 10,20 or 30 min after oral midazolam. We did not have a placebo group because: (1) this was a comparative study to compare the speed of onset of action or oral midazolam after 10,20 and $30 \mathrm{~min}$ and (2) the efficacy of oral midazolam at $30 \mathrm{~min}$. and the lack of placebo effect in this age group has been demonstrated previously. ${ }^{1,2}$ Sedation scores increased at the time of separation and mask application in all three groups but did not differ significantly among these groups at either time. The speed of onset of action of oral midazolam (ten minutes) is thus comparable with that reported for intranasal and rectal drug administration. 4,5

Although we were able to demonstrate excellent anxiolysis scores in all three groups at the time of separation from parents we could find no differences in these scores when compared with baseline. This is inconsistent with the results of McMillan et al. ${ }^{\prime}$ Previously, we found that anxiolysis scores increased after oral midazolam.' This inconsistency may be attributed in part to a difference in study design in that, in the present study, we assessed anxiolysis scores before measuring the vital signs or administering the midazolam whereas, in our previous study, anxiolysis was assessed only after midazolam. This could explain the greater anxiolysis scores before midazolam in the present study compared with those reported previously. ${ }^{1}$

The proposed therapeutic plasma threshold concentration for sedation with midazolam is $40 \mathrm{ng} \cdot \mathrm{ml}^{-1}$. Walbergh et al. demonstrated a very rapid increase in the plasma midazolam concentration to a mean peak of 72.2 $\mathrm{ng} \cdot \mathrm{ml}^{-1}$ within ten minutes of intranasal administration of $0.1 \mathrm{mg} \cdot \mathrm{kg}^{-1}$ midazolam. ${ }^{6}$ They explained this rapid increase by the very effective mucosal absorption of the drug. Payne et al. reported a plasma concentration of midazolam of $33.6 \mathrm{ng} \cdot \mathrm{ml}^{-1} 15 \mathrm{~min}$ after administration of midazolam $0.45 \mathrm{mg} \cdot \mathrm{kg}^{-1}$ via a nasogastric tube. ${ }^{7}$ Since midazolam has a pKa of 6.15 the majority of the drug is ionized in the presence of gastric fluid. ${ }^{8}$ Gastric absorption should thus be slow, but absorption should be more rapid from the duodenojejunal area. ${ }^{7,8} \mathrm{We}$ ad- ministered midazolam in a viscous chocolate-cherry syrup which may coat the oral mucosa with midazolam and augment oral trans-mucosal absorption. We therefore speculate that the rapid onset of action of oral midazolam in children is due to a combination of very efficient transmucosal oral absorption and to a lesser extent, gastrointestinal absorption.

There is often little time available for assessment and premedication of children in a busy ambulatory surgery setting. We have shown that oral midazolam is an effective premedication when given between 10 and $30 \mathrm{~min}$ before separation from parents. This brief interval of ten minutes will neither interfere with the rapid throughput typical of a busy day-surgery unit nor delay recovery and discharge from the ambulatory unit.

\section{References}

1 McMillan CO, Spahr-Schopfer IA, Sikich N, Hartley E, Lerman J. Premedication of children with oral midazolam. Can J Anaesth 1992; 39: 545-50.

2 Feld LH, Negus JB, White PF. Oral midazolam preanesthetic medication in pediatric outpatients. Anesthesiology 1990; 73: 831-4.

3 Weldon $B C$, Watcha MF, White PF. Oral midazolam in children: effect of time and adjunctive therapy. Anesth Analg 1992; 75: 51-5.

4 Wilton NCT, Leigh J, Rosen DR, Pandit UA. Preanesthetic sedation of preschool children using intranasal midazolam. Anesthesiology 1988; 69: 972-5.

5 De Jong $P C$, Verburg MP. Comparison of rectal to intramuscular administration of midazolam and atropine for premedication of children. Acta Anaesthesiol Scand 1988; 32: 485-9.

6 Walbergh EJ, Wills RJ, Eckhert J. Plasma concentrations of midazolam in children following intranasal administration. Anesthesiology 1991; 74: 233-5.

7 Payne K, Mattheyse FJ, Leibenberg D, Dawes T. The pharmacokinetics of midazolam in paediatric patients. Eur J Clin Pharmacol 1989; 37: 267-72.

8 Reves JG, Fragen RJ, Vinik HR, Greenblatt DJ. Midazolam: pharmacology and uses. Anesthesiology 1985; 62: $310-24$. 